\title{
Worries are the mother of many diseases: General practitioners and refugees in the Netherlands on stress, being ill and prejudice ${ }^{\text {it }}$
}

\author{
C. Titia Feldmann ${ }^{\mathrm{a}, *}$, Jozien M. Bensing ${ }^{\mathrm{b}}$, Arie de Ruijter ${ }^{\mathrm{c}}$ \\ ${ }^{a}$ Linnaeusparkweg 8 hs, 1098 EA Amsterdam, the Netherlands \\ ${ }^{\mathrm{b}}$ NIVEL, Utrecht, the Netherlands \\ ${ }^{\mathrm{c}}$ Faculty of Social and Behavioural Sciences, Tilburg University, the Netherlands
}

Received 24 May 2006; received in revised form 12 September 2006; accepted 20 September 2006

\begin{abstract}
Objective: To confront the views of refugee patients and general practitioners in the Netherlands, focusing on medically unexplained physical symptoms (MUPS).

Methods: The study is based on in depth interviews with refugees from Afghanistan $(n=36)$ and Somalia $(n=30)$. Additionally, semistructured interviews were conducted with 24 general practitioners. Text fragments concerning the relationship between mental worries and health or physical ailments were subject of a secondary analysis, the results of which are presented.

Results: Medically unexplained physical symptoms were a key issue for both refugees and GPs. The GPs saw MUPS as a significant part of the illness presentation by refugee patients. Refugees felt GPs were often prejudiced, too readily using their difficult background as an explanation for physical symptoms. A 'general narrative' circulating in the refugee communities undermines trust. The GPs applied different strategies in dealing with MUPS presented by their refugee patients. A 'human interest strategy' is distinguished from a 'technical strategy'. The results are discussed in the wider context of the literature on MUPS and patient satisfaction.

Conclusion: No fundamental difference in paradigms was found between refugees and GPs as to the negative influence worries and bad experiences can have on health. For a fruitful cooperation to develop, based on trust, GPs need to invest in the relationship with individual refugees, and avoid actions based on prejudice.

Practice implications: The importance of (a lack of) trust is underestimated in medical practice. Phenomena undermining trust are often out of sight for practitioners. Critical reflection is needed on the strategies practitioners employ to deal with MUPS.

(C) 2006 Elsevier Ireland Ltd. All rights reserved.
\end{abstract}

Keywords: Refugees; General practitioners; Medically unexplained physical symptoms; Prejudice; Trust; Stereotyping; Medical error

\section{Introduction}

Mrs. A22: 'GPs think that we Afghans always have psychological problems. That we come from a Third World country where there was war and we have suffered a lot and therefore we are all mad or psychologically ill. That is not

\footnotetext{
For more information on the Reflective Practice section please see: Hatem D, Rider EA. Sharing stories: narrative medicine in an evidencebased world. Patient Education and Counseling 2004;54:251-253.

* Corresponding author. Tel.: +31 20 6921716; fax: +31 206921716 .

E-mail addresses: ctfeld@xs4all.nl (C.T. Feldmann),

J.Bensing@nivel.nl (J.M. Bensing), ariederuijter@uvt.nl (A. de Ruijter).
}

true. Of course we have suffered a lot of misery, but this is another story. A gallstone has nothing to do with a psychological problem. [...] GPs here think that all our problems are psychological.'

Mrs. A22 is one of the Afghan women we interviewed for our research on the experiences of Dutch healthcare by refugees from Afghanistan and Somalia. The refugees in this study actually are 'former refugees': they have got a permit, they have settled in municipalities spread over the country, and have been busy building a new life for themselves for several years.

Since the general practitioner has a central role in Dutch healthcare and everybody living in the Netherlands is 
supposed to be on the list of a GP, we decided also to interview general practitioners about their experiences working with refugees from Afghanistan and Somalia, exploring their perceptions of refugees' problems and illness presentation, and the way they were dealing with these problems. The results of the refugee interviews and the GP interviews separately are being published elsewhere [1-3].

Virtually all GPs we interviewed mentioned the presentation of medically unexplained physical symptoms (MUPS) as an important part of the illness presentation by their refugee patients, and many of them acknowledged meeting difficulties in managing these complaints.

Dr. 18 (referring to the illness presentation of Afghan refugees): 'Many backaches and stomach complaints are according to me - expressions of psychological problems, but I cannot put my finger on it. [...] They think in different paradigms, they deal differently with illness, they see another connection between body and mind, more focused on the physical complaints.'

It seems both refugee patients and GPs have a problem here. Since the issue of physical complaints without an apparent medical explanation emerged as an important subject from both refugee and GP interviews, we decided to make it a central focus in our analysis. In this article we present the results of this analysis. The following questions will be addressed:

- What are the refugees' perspectives on health, illness and mental worries?

- What are their expectations from doctors?

- What are their problems dealing with Dutch doctors?

- What are the GPs' perspectives on medically unexplained physical symptoms presented by their refugee patients?

- Which strategies do the GPs use to address these complaints?

- Which problems do they encounter while assisting refugee patients with this type of complaints?

- What can we learn by confronting the refugees' and GPs' perspectives with each other?

We shall place our findings in the wider context of research on MUPS in general practice.

The doctors used different terminologies: 'somatisation', 'psychosomatic complaints', or 'stress-related complaints'. For our own analysis, we shall keep to the designation 'medically unexplained (physical) symptoms'. The other terms will frequently appear, however, when quoting others. Before presenting our study, we shall give a brief outline of the literature concerning MUPS.

Dealing with MUPS is a frequently occurring challenge for general practitioners - and not only in relation to refugee patients. Depending on the source and definition used, between 15 and $20 \%$ of consultations in general practice concern patients presenting with physical symptoms without apparent organic disease. Exploring the field of literature on this subject [4-6], the reader is confronted with different terminologies used by different practitioners (psychiatry, general medicine, general practice) and scholars (medicine, anthropology, psychology). Our search therefore included the terms 'somatisation', 'somatoform disorders', and 'somatic fixation'.

In a review article, Burton [4] gave the following definitions, which we quote here, because we think they contribute to semantic clarity:

- Medically unexplained physical symptoms (MUPS): physical symptoms for which no clear or consistent organic pathology can by demonstrated, although organ dysfunction may be an integral part of the symptoms;

- Somatisation: the process by which patients with psychological distress (as measured by psychiatric diagnostic interview or questionnaire) present physical symptoms to their doctor;

- Somatoform disorder: presentation of a specified number of physical symptoms without organic cause in the absence of other major psychiatric diagnosis; this includes DSM-IV somatisation disorder, considered part of the psychiatric domain [7], requiring presentation of at least eight out of 40 symptoms and an age of onset before 30 years.

Somatic fixation (not dealt with by Burton) points to the process going on between the 'somatising' patient and the doctor trying to heal $[8,9]$.

The literature confirms 'somatisation' or 'physical complaints without diagnosis' as being an important part of the illness presentation by refugees in different countries and situations [10,11]. Hondius and Van Willigen [12] found a correlation between the number of physical complaints and a history of physical torture. Lin's [13] findings among Asian refugees and immigrants in a US primary care situation point to an association between 'somatisation' and a high social burden in combination with lack of resources-both material, social, and personal. Refugees had a higher rate of somatisation than immigrants.

Coker [14] collected and analysed narratives from over 100 Southern Sudanese refugees living in Cairo and presenting with physical symptoms at a special clinic. The refugees told their stories, consistently interweaving physical sensations with their experiences of exile, loss, and marginalisation. Coker advocates listening to these narratives as 'a message about the existential crisis in which their (the refugees') community is embroiled.'

Burton [4] concludes his review article saying that "The notion that most MUPS are the result of a single process of somatisation (particularly the somatisation of mental distress), [...] is no longer supported by the evidence. There is now good evidence that physiology, personality, life experiences, health cognitions, and interactions with 
healthcare professionals are all important, and any new paradigm needs to include them."

The interaction and communication between doctors and patients have become central issues in the research on MUPS. From the comparison of three qualitative studies, May et al. [15] demonstrated that differences between doctor and patient about the interpretation of the presented complaints are an important source for conflict. General practitioners express frustration and powerlessness when dealing with this type of complaint [16]. Negative stereotyping of patients can play a role [17], and doctors often have wrong ideas about patients' explanatory models [18]. Patients employ their own tactics to convince the doctor of their point of view [19]. Doctors with a higher perceived workload, lower job satisfaction, and a lack of training in communication skills reported higher numbers of 'heartsink patients' in their practices [20].

Somatisation in general practice was found to be associated with damaging earlier life events, often unknown to the general practitioner [21,22]. Mollica [23] advocates the systematic assessment of the impact of traumatic life experiences in new primary care patients, especially refugees.

Management of MUPS has been another focus of study: what do GPs do and which strategies work? Kuyvenhoven [24] identified three parameters for quality of performance by GPs: attention paid to somatic aspects, patient orientation, and prevention of unnecessary harm, i.e. superfluous prescriptions and referrals. She was able to construct profiles of GPs in which more patient orientation correlated with less risk of unnecessary harm. Later observational studies have tried to clarify the dynamics of why GPs order physical interventions. Ring et al. [25] demonstrated from audio taped consultations that patients with unexplained physical symptoms often did not directly request physical interventionsbut the GPs felt pressurised by the style of presentation. GPs were found to offer little effective explanation or empathy in consultations with patients presenting MUPS [26].

Burton [4] found few studies concerning treatment of MUPS in primary care. Recognising and treating depression [27] and cognitive behavioural therapy [28] have appeared to be promising. Blankenstein [29] found reattribution to be a promising approach. In the refugee and trauma literature, body-oriented treatments are advocated, but they have mostly been developed in a mental healthcare setting [30,31]. The statement in 1997 that 'effective interventions are available' for treating medically unexplained physical symptoms [32] had apparently not yet become common knowledge in 2005 [33].

Having outlined the 'state of the art' above, we return to our interview material in order to explore how our results relate to the state of the art and possibly shed some new light on it.

\section{Methods}

\subsection{Procedure}

Since little research has been done eliciting refugees' views on the way the healthcare system serves them in countries of resettlement, we set up an open ended, explorative study to learn about their frames of reference, expectations and experiences concerning health and healthcare. Elements from grounded theory [34,35] were used in designing the study, during data collection and in the analytical process.

We held 25 in depth interviews with refugees from Somalia, involving 30 participants, and 24 with refugees from Afghanistan, involving 36 participants. The refugees were approached through refugee initiated community organisations, volunteers of the Dutch Council for Refugees and personal networks. In a later stage, some participants volunteered for an interview, after hearing about the study from other participants.

The participants lived in different municipalities in the Netherlands. The interviews lasted between 1.5 and $2 \mathrm{~h}$ and were conducted by the first author (a female, former general practitioner) with the help of a female Somali or Afghan assistant researcher interpreting and, where necessary, explaining issues. At different stages, two Somali women and three Afghan women were involved as assistantresearchers. All of them had academic education and were committed to the subject of the research. One of the Afghan women was a professional interpreter. All assistant researchers were fluent in Dutch and in their own language, had good knowledge of the specific terminology and strong communication skills. They were also important as 'cultural intermediaries' and assisted in developing a trust-based relationship with the participants. Eight of the Somali participants and nine of the Afghan participants were approached by the assistant researchers and therefore known to them. Ten Afghan interviews and three Somali interviews were conducted directly in Dutch by the first author alone. All interviews were recorded on tape with the consent of the participants and a verbatim transcription was made.

A topic list was designed with advice from refugee experts, and used in a flexible way, following the line of thought of participants. The topic list was adapted during the process of data collection, adding issues that appeared to be important during the interviews, such as 'stories heard from others'.

The first part of the interviews focused on participants' experiences with healthcare in their country of origin. In the second part they were asked to speak about their situation and health in the Netherlands, naturally leading to their experiences with healthcare. The narratives focused on their experiences with general practitioners. At the end of the interview participants were asked to formulate what health and illness mean to them, what their ideas are about causes of illness, and they were invited to make their own additions and recommendations. 
In a later stage we interviewed 24 GPs with Somali and/or Afghan refugee patients in their practice. Twenty-one of them responded to our letter of invitation, which was sent to a non-selective sample of 325 Dutch GPs in different (urban and rural) areas of the country. Three more GP interviews were realised through personal contacts. The GPs were therefore not the GPs of the refugees we had interviewed. In the developmental stage of the research we briefly considered the possibility of trying to interview refugees and GPs in pairs. We dropped this idea almost immediately, because of the expectation, and urgent advice we were given, that refugees will refuse to give an interview or not speak freely if they were asked whether their GPs could be interviewed later.

The GP interviews had a semi-structured character with open-ended questions. A senior medical student conducted 22 of the interviews, coached by the first author. The first author carried out three interviews, one of which was a follow-up interview to clarify specific issues. Twelve of the GP interviews were conducted by telephone and the other 12 face-to-face, according to the doctor's preference. The interviewer took notes during the interviews and elaborated on them conscientiously immediately afterwards. Three GP interviews were recorded on tape with the consent of the doctor and transcribed verbatim.

\subsection{Groups of participants}

\subsubsection{Afghan refugees}

Thirty-six Afghan participants took part in 24 interviews (a husband and wife giving an interview together are counted as 2 participants); 12 couples, 9 women alone, and 3 men alone. Their ages ranged between 18 and 66 years, and they had lived in the Netherlands for between 3 and 13 years. All participants were Muslims. The level of education of the participants varied; 12 had completed academic or higher vocational education, 16 a secondary or lower vocational education, 7 had received only primary education, and 1 elderly woman was illiterate.

Sixteen participants were unemployed, nine were employed, four were receiving some sort of training, three were doing voluntary work, and four were over 60 years of age. Twenty-three participants had acquired Dutch nationality, 13 had a refugee or humanitarian residence permit. Seven participants lived in a major city, 18 in a smaller city, and 11 in a village. Young, unmarried men were under represented among our participants, as compared to the Afghan population in the Netherlands [36].

\subsubsection{Somali refugees}

Thirty Somali participants took part in 25 interviews (a husband and wife giving an interview together are counted as 2 participants); 16 women have been interviewed alone or in the presence of small children, 5 women together with their husbands, and 4 men alone. Their ages ranged between 24 and 68 years, and they had lived in the Netherlands for between 6 and 15 years. All participants were Muslims. Eleven participants had completed academic or higher vocational education, 13 secondary or lower vocational education, 5 had received only primary education, and 1 woman was illiterate.

Sixteen participants, mostly women, were busy looking after their families, five female participants and two male participants were engaged in paid work, two men were over 60 years of age, one of whom was active in voluntary work, and one young man was a fulltime student. Apart from two women, all Somali participants had acquired the Dutch nationality. Nineteen participants lived in a major city, seven in a smaller city, and four in a village. Young, unmarried men were under represented among our participants, as compared to the Somali population in the Netherlands [36].

\subsubsection{General practitioners}

Among the 24 participating GPs, 17 were male and seven were female - a ratio similar to that of practising GPs in the Netherlands in 2003. The participating group was atypical in other characteristics: GPs under 40 years of age (36\% of GPs in the Netherlands) were under represented and GPs aged $50+(19 \%$ of GPs in the Netherlands) were over represented. GPs from strongly urbanised areas were also over represented, as were GPs working in group practices and health centres-50\% in the participating group, $30 \%$ of GPs in the Netherlands.

Fifteen of the 24 participating GPs worked 4 days or more in their practices, nine GPs less than 4 days. Except for one, all GPs were of Dutch origin. Twenty-one GPs had more than 5 years experience working with Afghan and Somali refugees, some up to 10 or 15 years. Most participants had both groups in their practice and three had only one of the two. The number of Somalis ranged between 3 and 250 per practice, the number of Afghans between three and 60. The practices varied widely in their percentage of patients of non-Dutch origin: from $97 \%$ in strongly urban practices to $1 \%$ in rural practices.

\subsection{Analysis}

The first author analysed and coded the transcripts of the refugee interviews, using the WinMAX software program [37] to organise the data and facilitate retrieval. The use of the software programme enhanced the consistency of the coding process, and facilitated cross-sectional comparison and the recoding of text fragments. After initial coding and cross-sectional comparison, a schematic presentation in short quotes was made of each refugee interview $[1,2]$. Using this method facilitated analysis along the time axis. In a process of constant comparative analysis, starting from some extreme cases, the refugee narratives were analysed. Personal experiences appeared to be intermingled with stories about other people's experiences. In the personal narratives 'critical episodes' could be distinguished, encounters with healthcare providers that left a positive 
or a negative mark in the participant's memory [1,2]. Participants also provided explanations for their negative experiences. The feeling of 'not having been taken seriously' by a healthcare provider was central in negative critical episodes. Explanations provided were mostly based on perceived prejudice or lack of interest from the provider's part.

The GP interviews were analysed and coded in the same way. A short profile was written for each doctor, linking interview results to doctor and practice variables. In an initial analysis, rough codes were assigned for the doctors' perceptions of the refugee groups, the problems the refugees presented to them, the way they dealt with these problems, and the constraints they met [3].

Dealing with MUPS emerged as one of the central themes in both the refugee and the GP interviews. In order to explore this topic further, we performed a secondary analysis of our interview data, both refugee interviews and GP interviews, introducing the code 'body and mind', which was attached to all statements concerning this theme. Further content analysis linking refugee statements to GP statements revealed agreements, disagreements, and bottlenecks, which form the body of this article.

\section{Results}

The perspectives of refugees and general practitioners are presented successively in the next section, under content headings derived from the analytical process.

\subsection{Perspectives of refugees}

\subsubsection{General narrative versus personal narratives}

The refugee participants frequently interspersed their personal narrative with stories they had heard from others friends or family members - in their respective communities about experiences with healthcare. Instead of discarding these 'second-hand' stories, we gratefully accepted and analysed them. In contrast to the variety of the personal narratives, the 'second-hand stories' had an overall negative content of prejudice, lack of good care for foreigners or refugees, and professional mistakes (sometimes with severe consequences). These stories functioned as a sort of shared backdrop-either contrasting with the personal narrative or underlining it. We introduced the concept of 'general narrative' for this phenomenon, which was identified in both the Afghan and Somali refugee communities.

\subsubsection{Refugees' concepts of health and illness}

Both Afghan and Somali participants, when asked to describe what health means to them, used terms like 'the most valuable thing a human being can have' and related it to physical functioning, as well as social, emotional, and mental functioning, and autonomy: to be able to think well, to radiate happiness, to work, to walk around and eat well, to relate to others, and to be independent. Exceptions were two young Afghan participants (A13 and A25), who specifically referred to health as 'something in the body' or the absence of physical impairments.

Illness, on the other hand, was referred to as 'the worst' and associated with loss of independence. The terminologies used by Somali and Afghan participants were strikingly similar and pointed to a comprehensive concept of health, in which autonomy was a central characteristic.

\subsubsection{Causes of illness-mental worries}

We asked all participants what, in their view, are causes of illness. Both Afghan and Somali participants mentioned a wide range of possible causes: climate and environment, bad food or lack of food, the will of God, lifestyle items like alcohol, drugs, and smoking, lack of hygiene, infections and 'bad' sexual contacts, lack of physical exercise, or too much physical strain. The single most frequently mentioned item, though, was mental worries or 'thinking too much' because of loneliness, unemployment, war experiences, loss of family members, being separated from family, or not being able to support family members in bad situations. Participants in 21 out of 24 Afghan interviews spontaneously mentioned this item, husband and wife agreeing completely in the interviews with couples.

Mrs. A02: 'Nerves play a role; the cause of physical complaints, thousands of complaints, lies in psychological problems.' 'We have a saying,' her husband adds, 'that worries are the mother of many diseases. [...] This expression is part of the culture of our country, a proverb of our older men, of our ancestors.'

There seems to be a difference between generations. Mr. and Mrs. A02, quoted here, belonged to the middle-aged generation and considered the notion of the link between worries and illness as part of their cultural heritage. Mrs. A25, who is much younger and arrived in the Netherlands at the age of 19 , said that before leaving her country she was not aware of the influence of emotional problems on the body, but she discovered it from her own experience.

Among the Somali participants there was less general agreement about worries or living in a bad situation as causes of illness: participants in 15 out of 25 interviews mentioned it. This still makes 'worries' the single most mentioned cause of illness, also by Somali participants. But contrary to the Afghan participants, Somali participants saw this as a new discovery, as part of their experience as exiles.

Mrs. S09: 'But about the mental problems and illness, that I learnt here. I never heard that in Somalia. [... ] [In Somalia] I have never seen someone who is ill because of stress or fear. [...] Maybe Somalia was an open country. People have their own family and they have more contact. I think in Somalia they don't have stress.'

The comprehensive concept of health was reflected in the way participants, both of Somali and Afghan origin, 
described their (ill) health in specific situations in the past or in the present. The present situation, i.e. the perception of self and others as persons not being able to fully participate in the new society and therefore unable to re-establish autonomy, was also described in terms of illness, by both Somali and Afghan participants:

Mrs. S15: 'Many refugees from Somalia are what we call 'outpatients'. Everybody is ill because of the situation, especially the men. They are sitting at home and they are not used to sitting at home. [...] There is no job for them here. That makes people ill.'

\subsubsection{Personal responsibility—strategies to stay healthy}

First and foremost participants felt responsible for their own health and situation. They were active in their endeavours to keep themselves healthy and sound. Being careful in the choice of food, being meticulous with hygiene, and taking regular physical exercise were mentioned by almost all of them.

Both Somali and Afghan participants mentioned a range of strategies to cope with their worries and bad memories: indulging in activities, praying, doing sports or other physical activity, listening to music, trying to think positively, talking with friends or family. Many participants combined different strategies.

Sharing the burden of worries by talking with family members or friends was the most frequently mentioned strategy, both by Afghans (10) and Somalis (17). But it was also a disputed strategy:

Mrs. A24 (a 29-year-old mother of two): 'In the beginning I thought it was good to talk about my experiences. But after two or three years in the Netherlands I noticed I became angrier and sadder when I talked about it. All these memories came back into my mind. Therefore I tried to forget everything. And each time these memories come back, I do something to forget. In this way I helped myself a lot. Four or five years ago, these memories jumped on me five times a day, nowadays only once a week. [...] The memories have a very bad influence on my life; they catch my joy of life. I don't want to live again.'

\subsubsection{Expectations from doctors}

Recognising that participants view health as a very valuable entity, closely linked to autonomy, and actively try to stay healthy, our next question was: what do participants expect from doctors, especially general practitioners? It is clear from the interviews that a doctor is primarily expected to address physical complaints; that is considered to be his expertise. You do not go to a doctor to discuss your problems:

Mr. A13: 'I never talked with anybody about my stress and pain, because I knew that it is part of my life. When you have left your country, you have to fight the pain and the stress. [...] Keep yourself busy with other things, with other people, playing football, studying, reading.'
But participants consider it important that a doctor shows interest in their person and their background.

Mr. A08: 'I don't think the doctor can help you to get a job. His job is the health of the patient. [...] But it is important that the doctor knows something about the background of the patient. He should know which things influence the health of the patient, in his country of origin and here.'

Kind words as a welcome are considered very important:

Mrs. A20: 'When you sit with a doctor and you hear kind words, that has an influence on your nerves, on your body. You start feeling better, healthier, than when the doctor is angry. It is all psychology.'

Anxiety about symptoms is an important motive to visit the GP, and the first need the participants expressed is the need to know the cause of the symptom. They expect a thorough physical examination. Fears related to symptoms can be very specific:

Mr. A15: 'Sometimes I get this idea that perhaps when I was so much under pressure, because of the strokes on my head (he refers to torture during his stay in prison in Afghanistan), that perhaps that is the cause of my headaches. [...] And sometimes I think, if no real examination is done, I cannot have certainty what causes this headache. First there must be a diagnosis [of] where it comes from. Now I don't watch TV, I don't worry about anything, only about my health, and still this headache remains the same.'

Several participants expressed the wish to be part of the discussions with the doctor on how their problem can best be addressed:

Mr. A16: 'I would want the doctor to say: You are my client. We have five minutes to discuss and find a solution together. Correct and accept each other. That is the right way.'

These expectations don't seem extraordinary: a positive, welcoming attitude, recognition and adequate examination of the physical complaint, resulting in an explanation that deals with specific fears, and an exchange of views on how to proceed. Still, a lot of complaints about Dutch GPs are circulating in both the Afghan and the Somali refugee communities. So what is going wrong?

\subsubsection{Refugees' problems with doctors}

Our analysis of both personal narratives and the 'general narrative' shows that refugees have problems with doctors who they feel do not take them or their complaints seriously: there is fear of misjudgement. Stories circulate in both the Afghan and the Somali communities about physical symptoms that for a long time were misjudged by doctors and in the end appeared to be caused by a serious physical disease.

Mrs. S24: 'Somali people don't trust Dutch doctors. [...] For instance, my friend, she died last week in this neighbourhood. 
She had a terrible headache for almost five years. She visited her GP several times, he sent her to the hospital for a photo. Nothing was found. Later she went into a coma because she had a tumour in her head. She died shortly after. And other Somalis hear that a young woman died like that. How can you have trust if you hear something like that? Somebody who lives in Europe and has a headache for five years, then suddenly dies. Like somebody living in the jungle without a doctor.'

Participants want to be approached as individuals, not as representatives of a group. With the understanding that they have suffered many bad experiences and that these can influence their present state of health, like Mrs. A22 quoted at the beginning of this article, they feel doctors focus too much on this 'refugee experience' at the cost of openminded attention to what is wrong with the individual patient:

Mr. S25: 'What angered me most was his generalising attitude that blocks everything: this person comes from Somalia, so he is traumatised.'

Paracetamol has become a metaphor by itself in refugee narratives. It is not so much the paracetamol as a medicament that is blamed, but it has become an unappreciated replacement for serious professional attention and human recognition.

Tranquillizers, more or less the counterparts of paracetamol, also figured in a number of narratives as substitutes for real professional interest in the patient:

Mrs. A09: 'After those nine months in the reception centre, I came to my house. [...] It started with headaches and pains in my neck and shoulders and body. [.. .] During two or three years I went to see the doctor and I got tranquillizers and sleeping tablets. And the doctor said: because you are here in a foreign country and you have gone through a lot of experiences, these are normal reactions because of the problems you have had in the past. For two or three years I got these tablets. [...] Until I told the doctor: I don't want to take the tablets again. One becomes addicted to them.'

Some participants felt they are too often identified with their past experiences of war and oppression, and that attention to their present situation and struggle is lacking:

Mr. A12: '[...] I want to move forward. [. . .] Maybe I have experienced a lot of bad things, but I don't want to talk about these bad things again. If I go back to these problems that I left behind, that drives me mad.'

\subsection{The general practitioners' perspective}

The GPs we were able to interview probably were more positively inclined towards refugee patients than the average Dutch GP: they were prepared to make the extra investment of giving an interview concerning this relatively small group in their practice. The general tone of the interviews was one of interest and commitment, though sometimes mixed with feelings of insufficiency and powerlessness. We did not come across statements with a discriminatory content.

\subsubsection{General practitioners on refugee problems}

With presentation of medically unexplained physical symptoms being such a central issue in the experience of the participating GPs, we focused our analysis on problem definitions they gave, difficulties they met, and management strategies they had developed. The GPs connected the presentation of a wide spectrum of physical complaints to the situation their refugee patients were living in, and also to their past experiences:

Dr.14: 'The Somali's don't root well in the Netherlands. [... ] Evident physical complaints; besides that, psychosocial and psychosomatic complaints, like headache, stomach ache, as a cover on top of the bad situation in which they are. They feel unhappy. [...] Restrained anger about their bad social situation.'

The doctors made a link to the level of education, not only for refugee patients, but also for other patients of Dutch and non-Dutch origin: people with less education more often present with this type of complaint, according to the participating GPs.

The supposed 'difference in paradigms' has been mentioned before when quoting Dr.18 in the introduction of this article. We now proceed to present an overview of management strategies as they arose from our GP interviews.

\subsubsection{How doctors deal with refugee problems}

From our interview data we can roughly make a division between 15 doctors who said they invest in the relationship with their refugee patients, and 9 others who seemed to do this less. We labelled the two strategies 'human interest strategy' and 'technical strategy'.

The 'human interest' GPs were more often older, had a longer experience of working with refugees, sometimes expressed a special interest working with these groups, and had larger groups of refugee patients in their practice.

The nine GPs following a 'technical strategy' spoke about their refugee patients in a more 'distant' way, stressing cultural differences, 'strangeness' of complaints, lack of education, and differences in thinking about health. They were more often (but not always) the doctors with fewer than 10 Somali and/or Afghan refugee patients in their practice and fewer years of experience working with them.

Both the 'human interest strategy' and the 'technical strategy' can take different varieties. Some components appeared in both strategies. Ten out of the 24 GPs we interviewed expressed feelings of powerlessness when dealing with these types of problems in their refugee patients. 


\subsubsection{Human interest strategy}

3.2.3.1. Investing in the relationship. Fifteen doctors who said they do invest in the relationship with refugee patients, saw this investment as a necessary basis for dealing with unexplained physical symptoms.

Dr. 03: 'Creating trust is an important aspect, to show that you are interested in the person, not only in the disease; to show that you want to know something about the context. Sometimes it is difficult to find time for it in a busy practice, but I see it is a worthwhile investment. [...] For refugees, where do you come from, how did you get here? [...] I ask about shocking events, specifically why they came to the Netherlands, whether they have family here and where the family is. [...] You should not do that when they have already been in the practice for six months. You have to separate it from the presentation of a problem. [...] This is what I worked out by trial and error.'

The GPs who had the most experience working with refugees stressed the importance of meeting each refugee patient as an individual, not as a representative of a group.

Dr. 24: 'Looking at Afghan and Somali refugees, you always have to approach people as individuals. You can only go on 'experience' to a very limited extent. [...] That complicates matters, but also makes it easy. You can just as well say, I'll wait and see who comes in, and whatever his or her story, I can always listen.'

3.2.3.2. Biopsychosocial approach. Eight GPs stated they follow a biopsychosocial approach in dealing with the 'stress-related complaints' of their refugee patients. These doctors seemed most satisfied with the approach they had developed, sometimes in the course of many years. They also felt their refugee patients were satisfied. Only two of these GPs expressed feelings of powerlessness.

Dr. 24: 'I tell people I am a doctor with a biopsychosocial approach. I look at both physical and psychological causes and I like to talk openly about that. [...] I purposely do it this way. Because if you talk too much about psychological aspects, people, not only Somalis, say that there is really something wrong with me, doctor. [...] This feeling, that physical complaints must have a physical cause, Somalis certainly have that. But the longer I work as a doctor, the more I wonder whether this is something specific for other cultures. [...] This biopsychosocial approach does justice to how people feel. [...] There are people who tell me: doctor, I am very tense these days, many problems ....'

3.2.3.3. 'Fishing' for the cause. Another strategy we distinguished is the 'fishing strategy'. The GP starts fishing for a psychological cause after somatic causes have been excluded-in this context the GPs mostly referred to traumatic experiences in the past. The 'fishing strategy', therefore, is different from the biopsychosocial approach.
Five participating GPs said they follow this strategy: three of them as part of a 'human interest strategy', two of them as part of a 'technical strategy'. These doctors did not appear to be very successful in their efforts; they expressed feelings of powerlessness more often than doctors who followed a 'biopsychosocial approach' right from the beginning.

\subsubsection{Technical strategy}

3.2.4.1. Keeping to a somatic approach. Four GPs stated they keep to a somatic approach as much as possible, three of them had less than 5 years experience in working with refugees. They connected their preference for this strategy to either language problems or a supposed inadequate insight on the part of their refugee patients, and often a combination of both. Doctors following this strategy seemed to do so as an alternative to personally investing in the relationship with their refugee patients. Three of them expressed feelings of powerlessness in helping refugee patients.

Dr. 04 (referring to refugees in general): 'The patient often has difficulty making the translation between physical complaints and a psychological cause. [...] I keep as much as possible to a somatic approach. The patient interview is often difficult because of the language barrier, so I request more diagnostic procedures. Some problems resolve themselves in the course of time.'

The other 'technical strategy' GPs combined the somatic approach with explaining, fishing, or referrals to a mental healthcare service or social worker, without really investing in the relationship themselves.

\subsubsection{Elements that occur in both 'human interest' and 'technical' strategies}

3.2.5.1. Explaining. The doctors mainly used language as an instrument: explaining what the complaint does or does not mean, but they felt hampered by the language barrier. Twelve doctors mentioned explaining as their main strategy, four of them as part of a biopsychosocial approach. They appreciated education and intelligence in their patients and associated this with a better insight into illness.

They often encountered resistance to their explanations. Some doctors attributed this to a lack of insight on the patient's part or to different cultural paradigms. Doctors who invested less in the relationship with their refugee patients also seemed to invest less in giving explanations.

3.2.5.2. Extra diagnostic procedures. Ten out of 24 doctors said they refer their refugee patients, or patients of nonDutch origin in general, for diagnostic procedures more often than their Dutch patients. These referrals can be part of broader strategies and were also mentioned by doctors who did invest in the relationship with their refugee patients. Pressure from the patient was most often given as an argument, but also uncertainty in the doctor's mind, and the wish to wind up the consultation: 
Dr. 03: 'In the beginning I tried to explain in words alone, but that did not work. I saw them coming back, so I took another route. [...] But I think we are also afraid sometimes that refugees could have unfamiliar types of diseases. That we could miss something. . (mentions tuberculosis and vitamin D deficiency).'

\subsubsection{Consultation with or referral to social work or} mental healthcare. Eighteen doctors mentioned consultation with or referral to social work or (specialised) mental healthcare, mostly as part of a broader approach. Twelve 'human interest' GPs refer to these professionals after investing in the relationship themselves. Six GPs seemed to refer without investing themselves, among them the three doctors with less than 5 years experience working with refugees. The others did not mention these referrals.

\section{Discussion and conclusion}

\subsection{Discussion}

Contrary to our expectations refugees and GPs generally speaking share the view that worries and bad experiences can have a negative influence on health. There seems to be a difference, though, between Afghan participants and Somali participants. Whereas the concept of worries influencing health was presented to us as part of Afghan cultural heritage, Somali participants saw it as part of their exile experience. Of course at the level of the individual consultation a difference in 'explanatory models' [38] may exist which, if not clarified, will prevent that 'mutual understanding' [39] is reached. Our design of reflective interviews with refugees and GPs, not engaged with each other, does not allow us to say anything about individual consultations. The phenomenon of doctors not being aware of their patients' explanatory models has already been pointed out by Helman in 1985 [18].

If paradigms do not differ fundamentally between refugees and GPs as far as the possible relationship between worries and health is concerned, then where is the problem?

The refugee participants feel they are too readily being identified with their traumatic past experiences and present hardships, at the cost of open-minded attention to their individual needs at a certain moment. The general narrative provides a body of evidence that this can lead to professional mistakes with sometimes-dramatic consequences, and therefore adds to the feeling in refugee patients that they have to be 'on their guard' when consulting a doctor. The trust, which is basic to a successful medical consultation, is not there. Innes et al. [40] described the consultation as a 'complex, adaptive system', composed of 'networks of agents'. Complex decision-making arises when agreement and certainty have to be traded for. The general narrative from the refugee community and earlier personal negative experiences are typical 'agents' in the 'network' of refugee patients that play a role in undermining trust, but which are unknown to the doctor. They are part of the 'internal context' [41] of the refugee patient.

Our refugee participants are very clear that first and foremost they need serious and unprejudiced attention for the physical aspects of their problem. If the doctor fails to acknowledge the physical complaint and to empathise with the underlying anxiety, explanations will not lead to accepted reassurance $[19,42,43]$. Anxiety and uncertainty related to physical symptoms are generally important driving forces for consulting a health professional $[44,45]$. Though doctors are aware of the risk of missing a serious disease, our interview data creates the impression that they tend to be more focused on preventing unnecessary harm by limiting interventions. Recently, Klein [46] analytically underlined the risk of doctors taking wrong decisions based on prejudice, stereotype, or overconfidence. Our minds have the tendency to be more focused on information that fits our pre-existing expectations rather than on conflicting information. Klein advises that it can be helpful to make a habit of seeking the opinion of colleagues.

We distinguished two mutually exclusive main strategies the GPs were applying: a 'human interest strategy' and a 'technical strategy'.

The GPs employing a 'technical strategy' speak in a rather 'distant' way about their refugee patients, emphasising cultural differences, 'strangeness' of complaints, and differences in paradigms: probably reflecting their difficulty in 'connecting' to these patients. They experience a 'cultural distance' [47]. For them, the refugee patients remain 'generalised others' [48]. It seems likely that a technical strategy, combined only with explanations and/or referrals, and without investment in the relationship, leads to dissatisfaction on the part of refugee patients, and often also on the part of the GP.

The GPs applying the 'human interest strategy' seemed more satisfied with their approach, especially if they combined it with a systematic biopsychosocial approach. Satisfaction on the part of the GP implied their belief that the refugee patients were satisfied. Fairhurst and May [49] related GPs' satisfaction with consultations to their communication and reasoning style. The GPs were more satisfied with consultations where they felt they had 'connected' to the patient, resulting in 'inductive knowledge' of patients, rather than 'deductive knowledge' based on mere facts.

There is an interesting and heartening parallel between what refugees expect from doctors, according to our interview data, and what we tend to call the 'best practices' of the GPs. Interest in the person and her/his background, showing a welcoming attitude, serious and careful history taking plus a physical examination, seeking agreement on possible explanations, and further discussion on the course to follow figure in both refugees' expectations and doctors' best practices. This strategy is in line with recommendations 
in the MUPS literature [4]. Asking about the way refugee patients deal with their situation and worries may be a useful addition, and helps to shift the 'locus of control' partially back to the patient [50], creating an atmosphere of joint responsibility [51].

The literature on MUPS relates requests for diagnostic interventions to 'perceived patient pressure' [25,52]. GPs often miss cues to start discussing psychosocial issues [53,54]. Ring et al. [26] concluded that the focus of attention should be more on a doctor's tendency to offer somatic interventions and neglect psychological cues, than on special characteristics of patients. Our interviews illustrate that GPs sometimes consciously order diagnostic interventions to wind up the consultation or because they feel unable to communicate in another way.

The question arises as to how far refugee patients are different from other patients in general practice. In a review of studies concerning patient views on quality of care in general practice, Rees Lewis [45] concludes that nearly all studies emphasise communication as one of the aspects of a consultation most indicative of quality in the eyes of the patient. From his meta-analysis, the following emerge as the top four items (in order of significance) correlating with general satisfaction:

- GP gives enough information

- Like GP as a person

- GP spends enough time on consultation

- GP has good medical skills

Looking at these items and having listened to our refugee participants, but also reflecting on the wider MUPS literature, we can conclude that communication tuned to the individual patient is of central importance, together with clinical competence. Safran et al. [55] found in a large survey among primary care patients that not only satisfaction but also self-reported health improvements correlated strongly with integration of care, thoroughness of physical examination, communication, comprehensive knowledge of patients, and trust. Patients, refugees or otherwise, want and need professionally competent doctors with good interpersonal skills.

\subsection{Conclusion}

Surprisingly, no fundamental difference in paradigms was found between refugees and GPs as to the negative influence worries and bad experiences can have on health. But refugees felt GPs were often prejudiced towards them, too easily bringing up psychological explanations for their physical complaints. A 'general narrative' circulating in the refugee communities, with an overall negative content of prejudice, lack of good care for foreigners or refugees, and professional mistakes with serious consequences, undermines trust. General practitioners were not aware of this 'internal context' of their refugee patients. For a fruitful cooperation to develop, based on trust, GPs need to invest in the relationship with individual refugees, and avoid statements or actions based on stereotypes and prejudice. There is a heartening parallel between refugees' expectations and GPs' best practices.

More qualitative and quantitative research is needed to assess whether a 'general narrative' phenomenon also exists in other refugee communities, and how widespread it is.

Systematic introduction and evaluation, first qualitatively and later quantitatively, of an introductory consultation with new refugee patients could establish the value and best elaboration of this extra investment in general practice.

Direct observation, visual registration and later (qualitative) analysis of consultations between general practitioners and refugee patients, combined with eliciting refugees' expectations and level of trust before the consultation, and both the GPs' and the refugees' assessments afterwards, can help to raise awareness of possibilities for improvement in specific practices.

\subsection{Practice implications}

We feel our findings have the following implications for practice:

- Early investment in the relationship with new refugee patients may be crucial to establishing a basis of trust and dealing with unexplained physical symptoms effectively.

- Asking (refugee) patients about their situation and the way they are dealing with it, separate from the complaint that is being presented, helps to create an atmosphere of joint responsibility.

- A physical complaint always deserves a thorough physical examination.

- The tendency to stereotype refugee patients may be a serious pitfall for practitioners.

- Critical reflection by practitioners is needed on strategies they employ for dealing with unexplained physical symptoms.

- Professional errors by medical practitioners have a long life circulating as part of the 'general narrative' in refugee communities, undermining trust. A more open climate when dealing with professional mistakes, especially towards the patients involved and their relatives, may help to address this phenomenon.

\section{Acknowledgements}

We thank COA, the Central Agency for the reception of asylum seekers in the Netherlands, and the Utrecht University for their financial support-without which this research would not have been possible. 


\section{References}

[1] Feldmann CT, Bensing JM, de Ruijter A, Boeije HR. Somali refugees' experiences with their general practitioners: frames of reference and critical episodes; submitted for publication.

[2] Feldmann CT, Boeije H, Bensing JM, de Ruijter A. Afghan refugees in the Netherlands and their general practitioners: to trust or not to trust? Sociol Health Ill; in press.

[3] Feldmann CT, Mol SSL, Bensing J, de Ruijter A, Boeije H. Dutch general practitioners and refugee patients: dealing with unexplained physical symptoms: a qualitative study; submitted for publication.

[4] Burton C. Beyond somatisation: a review of the understanding and treatment of medically unexplained physical symptoms (MUPS). Brit J Gen Pract 2003;53:231-9.

[5] Mumford DB, Devereux TA, Maddy PJ, Johnston JV. Factors leading to the reporting of 'functional' somatic symptoms by general practice attenders. Brit J Gen Pract 1991;41:454-8.

[6] Peveler R, Kilkenny L, Kinmonth AL. Medically unexplained physical symptoms in primary care: a comparison of self-report screening questionnaires and clinical opinion. J Psychosom Res 1997;42: 245-52.

[7] Escobar JI, Gara MSRC, et al. Somatisation disorder in primary care. Brit J Psychiat 1998;173:262-6.

[8] Grol R. To heal or to harm. The prevention of somatic fixation in general practice. London: Royal College of General Practitioners; 1981

[9] Biderman A, Yeheskel A, Herman J. Somatic fixation: the harm of healing. Soc Sci Med 2003;56:1135-8.

[10] van Willigen LHM, Hondius AJK, van der Ploeg HM. Health problems of refugees in the Netherlands. Trop Geogr Med 1995;47:11824.

[11] Adams KM, Gardiner LD, Assefi N. Healthcare challenges from the developing world: post-immigration refugee medicine. Brit Med J 2004;328:1548-52.

[12] Hondius A, van Willigen LHM, Kleijn WC, van der Ploeg HM. Health problems among Latin American and middle-eastern refugees in the Netherlands: relations with violence exposure and ongoing sociopsychological strain. J Trauma Stress 2000;13:619-34.

[13] Lin EHB, Carter WB, Kleinman AM. An exploration of somatization among Asian refugees and immigrants in primary care. Am J Public Health 1985;75:1080-4.

[14] Coker EM. "Traveling pains": embodied metaphors of suffering among Southern Sudanese refugees in Cairo. Cult Med Psychiat 2004;28:15-39.

[15] May C, Allison G, Chapple A, et al. Framing the doctor-patient relationship in chronic illness: a comparative study of general practitioners' accounts. Sociol Health Ill 2004;26:135-58.

[16] Wileman L, May C, Chew-Graham CA. Medically unexplained symptoms and the problem of power in the primary care consultation: a qualitative study. Fam Pract 2002;19:178-82.

[17] Raine R, Carter S, Sensky T, Black N. General practitioners' perceptions of chronic fatigue syndrome and beliefs about its management, compared with irritable bowel syndrome: qualitative study. Brit Med J 2004;328:1354-6.

[18] Helman CG. Communication in primary care: the role of patient and practitioner explanatory models. Soc Sci Med 1985;20:923-31.

[19] Salmon P. Patients who present physical symptoms in the absence of physical pathology: a challenge to existing models of doctor-patient interaction. Patient Educ Couns 2000;39:105-13.

[20] Mathers N, Jones N, Hannay D. Heartsink patients: a study of their general practitioners. Brit J Gen Pract 1995;45:293-6.

[21] Portegijs PJM, Jeuken FMH, van der Horst FG, Kraan HF, Knottnerus JA. A troubled youth: relations with somatization, depression and anxiety in adulthood. Fam Pract 1996;13:1-11.

[22] Mol SSL. Trauma, life events and PTSD; a challenge for patients and family doctors [dissertation]. Maastricht, the Netherlands: Unigraphic; 2002.
[23] Mollica RF. Assessment of trauma in primary care. JAMA 2001;285:1213.

[24] Kuyvenhoven MM. Quality of performance of general practitioners confronted with patients' non-specific complaints [dissertation]. Utrecht: Elinkwijk BV; 1988.

[25] Ring A, Dowrick C, Humphris G, Salmon P. Do patients with unexplained physical symptoms pressurise general practitioners for somatic treatment? A qualitative study. Brit Med J 2004;328: $1057-60$.

[26] Ring A, Dowrick CF, Humphris GM, Davies J, Salmon P. The somatising effect of clinical consultation: what patients and doctors say and do not say when patients present medically unexplained physical symptoms. Soc Sci Med 2005;61:1505-15.

[27] Morriss RK, Gask L, Ronalds C, et al. Clinical and patient satisfaction outcomes of a new treatment for somatised mental disorders taught to general practitioners. Brit J Gen Pract 1999;49:263-7.

[28] Lidbeck J. Group therapy for somatization disorders in general practice: effectiveness of a short cognitive-behavioural treatment model. Acta Psychiatr Scand 1997;96:14-24.

[29] Blankenstein NAH. Somatising patients in general practice; reattribution, a promising approach [dissertation]. Amsterdam: PrintPartners Ipskamp; 2001.

[30] Rothschild B. The body remembers. New York/London: W.W. Norton \& Company; 2000.

[31] Levine PA, Frederick A. Waking the tiger. Berkeley, California: North Atlantic Books; 1997.

[32] Mayou R, Sharpe M. Treating medically unexplained physical symptoms; effective interventions are available. Brit Med J 1997;315: $561-2$.

[33] Rosendal M, Olesen F, Fink P. Management of medically unexplained symptoms. Includes diagnosis, specific treatments, and appropriate communication. Brit Med J 2005;330:4-5.

[34] Glaser BG, Strauss AL. The discovery of grounded theory: strategies for qualitative research. New York: Aldin Publishing Company; 1967.

[35] Weiss RS. Learning from strangers. The art and method of qualitative interview studies. New York: Free Press; 1994.

[36] van den Tillaart H, Olde Monnikhof M, van den Berg S, Warmerdam J. Nieuwe etnische groepen in Nederland. Ubbergen, the Netherlands: Tandem Felix; 2000.

[37] Kuckartz U. WinMAX 97. Scientific text analysis for the social sciences. Berlin, Germany: BSS (Büro für Softwareentwicklung und Sozialforschung); 1998.

[38] Kleinman A. Patients and healers in the context of culture. Berkeley: University of California Press; 1980.

[39] van Wieringen JCM, Harmsen JAM, Bruijnzeels M. Intercultural communication in general practice. Eur J Public Health 2002;12: 63-8.

[40] Innes AD, Campion PD, Griffiths FE. Complex consultations and the 'edge of chaos'. Brit J Gen Pract 2005;55:47-52.

[41] Helman CG. The role of context in primary care. J R Coll Gen Pract 1984;34:547-50.

[42] Dowrick C, Ring A, Humphris G, Salmon P. Normalisation of unexplained symptoms by general practitioners: a functional typology. Brit J Gen Pract 2004;54:165-70.

[43] Kessler D. Normalisation: horrible word, useful idea. Brit J Gen Pract 2004;54:163-4.

[44] Cameron L, Leventhal EA, Leventhal H. Symptom representations and affect as determinants of care-seeking in a community-dwelling, adult sample population. Health Psychol 1993;12:171-9.

[45] Rees Lewis J. Patient views on quality care in general practice: literature review. Soc Sci Med 1994;39:665-70.

[46] Klein JG. Five pitfalls in decisions about diagnosis and prescribing. Brit Med J 2005;330:781-4.

[47] Redmond MV. Cultural distance as a mediating factor between stress and intercultural communication competence. Int $\mathrm{J}$ Intercult Rel 2000;24:151-9. 
[48] Wallace AFC. Culture and personality, 2nd ed., New York: Random House; 1970.

[49] Fairhurst K, May C. Knowing patients and knowledge about patients: evidence of modes of reasoning in the consultation? Fam Pract 2001;18:501-5.

[50] Jones R. Irritable bowel syndrome:management of expectations and disease. Brit J Gen Pract 2004;54:490-1.

[51] Bensing JM, Verhaak PFM. Somatisation: a joint responsibility of doctors and patients. Lancet 2006;367:452-4. February 11.

[52] Little P, Dorwerd M, Warner G, Stephens K, Senior J, Moore M. Importance of patient pressure and perceived pressure and perceived medical need for investigations, referral and prescribing in primary care: nested observational study. Brit Med J 2004;328: 444-6.

[53] Salmon P, Dowrick CF, Ring A, Humphris GM. Voiced but unheard agendas: qualitative analysis of the psychosocial cues that patients with unexplained symptoms present to general practitioners. Brit $\mathbf{J}$ Gen Pract 2004;54:171-6.

[54] Levinson W, Gorawara-Bhat R, Lamb J. A study of patient clues and physician responses in primary care and surgical settings. JAMA 2000;284:1021-7.

[55] Safran DG, Taira DA, Rogers WH, Kosinski M, Ware JE, Tarlov AR. Linking primary care performance to outcomes of care. J Fam Pract 1998;47:213-20. 